\title{
Height and age adjustment for cross sectional studies of lung function in children aged 6-11
} years

\author{
Susan Chinn, Roberto J Rona
}

\begin{abstract}
Background No standard exists for the adjustment of lung function for height and age in children. Multiple regression should not be used on untransformed data because, for example, forced expiratory volume $\left(F E V_{1}\right)$, though normally distributed for height, age, and sex, has increasing standard deviation. A solution to the conflict is proposed.
\end{abstract}

Methods Spirometry on representative samples of children aged 6.5 to 11.99 years in primary schools in England. After exclusion of children who did not provide two repeatable blows 910 white English boys and 722 girls had data on FEV 1 and height. Means and standard deviations of FEV $_{1}$ divided by height were plotted to determine whether logarithmic transformation of FEV , was appropriate. Multiple regression was used to give predicted FEV , for height and age on the transformed scale; back transformation gave predicted values in litres. Other lung function measures were analysed, and data on inner city children, children from ethnic minority groups, and Scottish children were described.

Results After logarithmic (ln) transformation of $F E V_{1}$ standard deviation was constant. The ratios of actual and predicted values of $F E V_{1}$ were normally distributed in boys and girls. From the means and standard deviations of these distributions, and the predicted values, centiles and standard deviation scores can be calculated.

Conclusion The method described is valid because the assumption of stable variance for multiple regression was satisfied on the $\log$ scale and the variation of ratios of actual to predicted values on the original scale was well described by a normal distribution. The adoption of the method will lead to uniformity and greater ease of comparison of research findings.

Department of Public Health Medicine, United Medical and Dental Schools of Guy's and St Thomas's Hospitals, St Thomas's Campus, London SE1 7EH

$S$ Chinn

R J Rona

Reprint requests to:

Miss S Chinn

Accepted 3 March 1992 the construction of reference centiles and in the analysis of lung function in relation to respiratory illness, passive smoking, or other effects, and a method needs to found that is appropriate for both situations.

Some authors have used multiple regression of untransformed lung function on age and height, for each sex separately, sometimes apparently without question. ${ }^{12}$ However, many authors have considered this inadequate, some including quadratic or even cubic terms in height or age, ${ }^{34}$ but rather more log transforming lung function and height and other independent variables if used. ${ }^{5-8}$ Some have used complex models in a mixture of transformed and untransformed variables, ${ }^{9}$ while others have constructed indices of lung function for height. ${ }^{10}$

Although not stated, it can be assumed that authors who analysed untransformed lung function did so because they found their measures to be approximately normally distributed for height, age, and sex of children. Those choosing the log transformation noted that this stabilised the variance of lung function, which increases with height and age if untransformed, ${ }^{8}$ but have ignored the nonnormality of the transformed variables. The conflict between normalising and variance stabilising transformations seems to exist at least for peak expiratory flow rate (PEFR), forced vital capacity (FVC), and forced expiratory volume in one second $\left(\mathrm{FEV}_{1}\right)$, but no previous author has addressed this conflict.

Although achieving homoscedasticity-that is, stabilising variance-is more important than normalising distributions for analysis of variance and regression analysis, it is desirable, at least for centile estimation, to use the normal distribution. In theory the problem of centile estimation could be dealt with by dividing children into age and height subgroups, estimating means and standard deviations on the scale giving a normal distribution, and then smoothing the means and standard deviations using some suitable function of age and height before deriving the centiles. This works well for height itself, ${ }^{11}$ for which only age need be taken into account, but would require far more data on lung function than are likely to be available. Achieving homoscedasticity is therefore important for centile estimation as it enables centiles to be estimated relative to the predicted value for height and age from a single distribution. If normality can be achieved it provides simple and efficient estimation of centiles. 
Bland et al considered the problem of constructing centiles of birth weight, which is normally distributed for a given gestational age but shows increasing variance with gestational age. ${ }^{12}$ They found that if $\log$ (birth weight) was regressed on gestational age the back transformed (antilogged) residuals were both homoscedastic and normally distributed. We used the method in relation to $\mathrm{FEV}_{1}$ in children and report results for FVC and forced expiratory flow rate over the mid portion of the curve $\left(\mathrm{FEF}_{25-75}\right)$ and for $\mathrm{FEF}_{75-85}$, which enables centiles for these measures to be calculated. Calculation of predicted values for ethnic minority groups is discussed.

\section{Methods \\ SUBJECTS \\ Data on lung function were collected in a subsample of areas that took part in the national study of health and growth in 1987 and $1988 .{ }^{13}$ This is a surveillance study of schoolchildren aged 5 to 11 years in which data are collected from a representative sample of English chil- dren in even years, from inner city and ethnic minority children in odd years, and from a representative sample of Scottish children over both years. For pragmatic reasons lung func- tion testing was carried out only in areas in which time was available during regular field- work and therefore, with some exceptions, in the areas of smaller sample size. The main analysis reported in this paper was carried out on data from white children in the English representative sample, of whom 2486 were eligible for inclusion. The English inner city sample contained 1895 eligible children, who were subdivided into white, Afro-Caribbean, Urdu, Gujarati, Punjabi speaking, other Indian subcontinent, or other, according to the language spoken at home and the fieldworker's assessment. ${ }^{13}$}

\section{MEASUREMENTS}

Only children in classes in which the majority were aged 7 years or more at the start of the school years had their lung function measured, which was carried out using a spirometer (Vitalograph Model S) with spirogram and digital printout. After calibration of the machine, instruction was given by a trained fieldworker to the children in small groups with a demonstration. Each child tried three times without wearing a noseclip and with a minimum exhalation time of $1.5 \mathrm{~s}$, and the results were recorded unless the fieldworker judged a blow to be in error from the spirogram. Limitations on time for fieldwork precluded further attempts. A child was not measured if the teacher informed the fieldworker that the child had a bad heart or was otherwise severely ill. In this analysis data for a child with asthma who had used an inhaler that morning were excluded. All measurements were made in May, June, or autumn and no correction at body temperature and ambient temperature was applied.

FEV , from the best blow, defined as the greatest sum of $\mathrm{FVC}$ and $\mathrm{FEV}_{1}$, was analysed in all children satisfying the above criteria, as well as in the smaller number in whom the two best $\left(\mathrm{FVC}+\mathrm{FEV}_{1}\right)$ measurements agreed to within $5 \%$; only the results in those having two best $\left(\mathrm{FVC}+\mathrm{FEV}_{1}\right)$ measurements within $5 \%$ agreement are reported in detail. The definition of best blow accords with the American Thoracic Society recommendation for $\mathrm{FEF}_{25-75}$ and $\mathrm{FEF}_{75-85} \cdot{ }^{14}$

Height was measured on a Holtain Stadiometer to the last complete $0 \cdot 1 \mathrm{~cm}$, as described by Tanner et $a l,,^{15}$ and $0.05 \mathrm{~cm}$ added before analysis.

\section{ANALYSIS}

Only the analysis of $F E V_{1}$ is described in detail. To determine whether $\mathrm{FEV}_{1}$ satisfied the criterion for $\log$ transformation boys and girls were divided into $5 \mathrm{~cm}$ height groups. Most $(98.9 \%)$ of the children fell in the nine groups from $\geqslant 115 \mathrm{~cm}$ to $\geqslant 155 \mathrm{~cm}$, which ranged in size from 10 children to 288 children, but only the $155+\mathrm{cm}$ groups had fewer than 40 children. Mean and standard deviation were calculated for $F E V_{1}$ within each group and plotted against each other to check that standard deviation was proportional to mean value. Multiple regression of $\ln \left(\mathrm{FEV}_{1}\right)$ on $\ln$ (height) and $\ln$ (age) was used to determine equations for predicted $\ln \left(\mathrm{FEV}_{1}\right)$ in boys and girls, where $\ln$ denotes logarithm to base e. The distributions of the residuals - that is, differences between actual $\ln \left(\mathrm{FEV}_{1}\right)$ and its predicted value for each child-were found and re-examined after antilogging each residual to determine which distribution was the more normally distributed. Means and standard deviations of the antilogged residuals were calculated, providing a method of calculating centiles and standardised scores. A similar procedure was carried out for FVC, $\mathrm{FEF}_{25-75}$, and $\mathrm{FEF}_{75-85}$, which were taken from the best curve as defined.

Participation, defined as the child providing at least one useful blow, was analysed by logistic regression in relation to age and sex using the generalised linear interactive modelling (GLIM) program, ${ }^{16}$ as was ability to perform a repeatable blow. Ability to perform a useful blow was additionally analysed in relation to wheeze and asthma as reported on a self administered questionnaire, usually completed by the child's mother.

\section{Results}

RESPONSE

A small number of non-white children were omitted from the English representative sample because ethnic group differences were expected, leaving a total of 2486 children aged from 6.5 to less than 12 years eligible for lung function in this sample. The number of children excluded for reasons of no lung function, use of inhaler, or leak in the Vitalograph tube are given for each sample in table 1 . Children who gave only one valid blow or whose two best blows differed by $5 \%$ or more (table 1 ) were omitted from the results given in detail. In the Scottish representative sample and English inner city samples a greater proportion of 
Table 1 Response to lung function in English representative, English inner city, and Scottish representative samples. Values are numbers (percentages of children)

\begin{tabular}{|c|c|c|c|}
\hline & $\begin{array}{l}\text { English } \\
\text { representative sample } \\
(1988)^{\star}\end{array}$ & $\begin{array}{l}\text { English } \\
\text { inner city sample } \\
\text { (1987) }\end{array}$ & $\begin{array}{l}\text { Scottish } \\
\text { representative sample } \\
(1987+1988)\end{array}$ \\
\hline \multicolumn{4}{|l|}{ Reasons for no lung function result: } \\
\hline Refusal & 0 & 4 & 1 \\
\hline Absence & 133 & 115 & 23 \\
\hline Bad heart or severely ill & 5 & 4 & 4 \\
\hline No valid blow & 47 & 142 & 46 \\
\hline Total & $185(7 \cdot 4)$ & $265(14 \cdot 0)$ & $74(11 \cdot 7)$ \\
\hline \multicolumn{4}{|l|}{ Reason why valid blow excluded: } \\
\hline Inhaler used & 60 & 32 & 7 \\
\hline Bad heart or severely ill & 2 & 0 & 0 \\
\hline Leak in tube & 0 & 0 & 54 \\
\hline Total & $62(2 \cdot 5)$ & $32(1 \cdot 7)$ & $61(9 \cdot 6)$ \\
\hline Only one valid blow & $98(3 \cdot 9)$ & $138(7 \cdot 3)$ & $27(4 \cdot 3)$ \\
\hline Best two blows differed by $\geqslant 5 \%$ in $\left(\mathrm{FVC}+\mathrm{FEV}_{1}\right)$ & $458(18 \cdot 4)$ & $407(21 \cdot 5)$ & $104(16 \cdot 4)$ \\
\hline Acceptable lung function but no height data & 1 & 3 & 0 \\
\hline Included in analysis & $1682(67 \cdot 7)$ & $1050(55 \cdot 4)$ & $368(58 \cdot 0)$ \\
\hline Total eligible & $2486(100)$ & $1895(100)$ & $634(100)$ \\
\hline
\end{tabular}

*White children only.

children were excluded for reasons of absenteeism or failure to provide a valid blow. A leaky Vitalograph tube caused a problem in one Scottish area, and a greater proportion of inner city children gave non-repeatable blows. There remained $55 \cdot 4 \%$ of inner city children and $58.0 \%$ of Scottish children with data meeting the criteria for inclusion in the analysis, compared with $67 \cdot 7 \%$ in the English representative sample. The main analysis here reported is of the data on the English representative sample, 1682 children ( 910 boys and 772 girls).

Useful participation, defined as giving at least one valid blow, increased with age $(\mathrm{p}<0.001)$ and varied significantly between study areas $(\mathrm{p}<0.001)$. The same was true when analysis was confined to those whose data were not rejected for reasons of illness or use of inhalerthat is, ability to perform a useful blow increased with age. Within area and adjusted for age ability to perform a useful blow was lower in children with persistent wheeze than in children with no symptoms $(\mathrm{p}<0.05)$.

Means and standard deviations of $\mathrm{FEV}_{1}$ by sex and age group are shown in table 2 for the English representative sample. Increasing variance with age was found for boys and girls.

\section{TRANSFORMATION OF LUNG FUNCTION}

The standard deviations of $\mathrm{FEV}_{1}$ within $5 \mathrm{~cm}$ height groups is shown plotted against mean value in figure 1 . The standard deviations increased with mean value and could be assumed to proportional to the mean value as

Table 2 Distribution of $F E V_{1}$ (l) for white children in English representative sample by sex and age

\begin{tabular}{|c|c|c|c|c|}
\hline \multirow[b]{2}{*}{ Age (years) } & \multicolumn{2}{|c|}{ Boys $(n=910)$} & \multicolumn{2}{|c|}{ Girls $(n=772)$} \\
\hline & $n$ & Mean ( $S D)$ & $n$ & Mean $(S D)$ \\
\hline$\geqslant 6$ & 11 & $1.38(0.20)$ & 6 & $1.42(0.17)$ \\
\hline$\geqslant 7$ & 97 & $1.54(0.24)$ & 85 & $1.46(0.23)$ \\
\hline$\geqslant 8$ & 209 & $1.71(0.27)$ & 182 & $1.59(0.28)$ \\
\hline$\geqslant 9$ & 236 & $1.94(0.32)$ & 179 & $1.78(0.27)$ \\
\hline$\geqslant 10$ & 225 & $2.07(0.29)$ & 179 & $1.97(0.30)$ \\
\hline$\geqslant 11$ & 132 & $2.25(0.36)$ & 141 & $2.23(0.38)$ \\
\hline
\end{tabular}

the intercept of the regression line did not differ significantly from zero $(p>0 \cdot 1)$ in boys or girls. This suggested the need for logarithmic transformation to stabilise variance ${ }^{17}$; figure 2 shows little relation between standard deviation and the mean of $\ln \left(\mathrm{FEV}_{1}\right)$.

\section{RELATION TO HEIGHT AND AGE}

$\operatorname{Ln}\left(\mathrm{FEV}_{1}\right)$ is shown plotted against $\ln$ (height) in figure 3, the relation being reasonably smooth and linear. $\mathrm{FEV}_{1}$ was significantly $(\mathrm{p}<0.001)$ related to $\ln$ (height) and to $\ln ($ age $)(p<0.001)$ in girls but not boys. Non-linearity, as assessed by quadratic and cubic terms in $\ln$ (height) and ln(age), was not significant $(p>0.05)$. The regression equations are given in table 3.

\section{DISTRIBUTIONS OF RESIDUALS}

Distributions of residuals on the ln scale were negatively skewed, as shown for $\mathrm{FEV}_{1}$ in boys in figure 4. Antilogging the residuals produced greater symmetry, as illustrated in figure 5 . The means and standard deviations of the antilogged residuals, which are ratios of actual to predicted $\mathrm{FEV}_{1}$, are given in table 3 . The information in table 3 can be used to calculate centiles of $\mathrm{FEV}_{1}$ for height and age or standard deviation scores for individual children, which

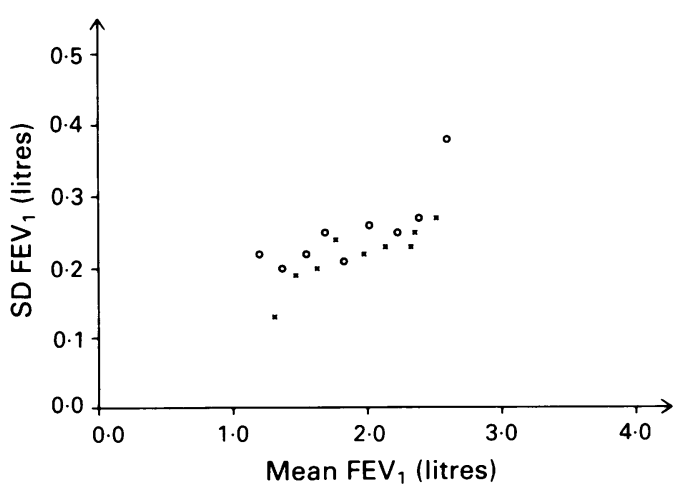

Figure 1 Standard deviations of FEV, plotted against mean values for white boys $(\times)$ and girls $($ ) in English representative sample. 
Figure 2 Standard deviations of $\ln \left(F E V_{1}\right)$ plotted against mean values for white boys $(x)$ and girls () in English representative sample.

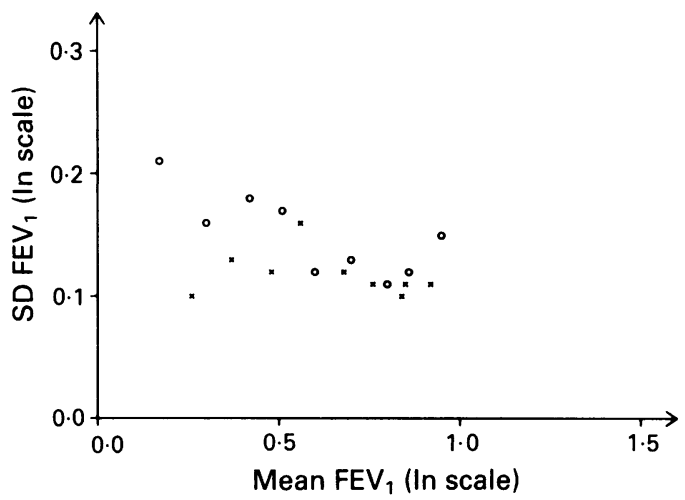

can be used in subsequent analyses as the appropriate measure of height and age adjusted lung function. This is described in the appendix.

FEV, FEF $_{25-75}$, AND FEF $_{75-85}$

Outlying values of $\mathrm{FEF}_{25-75}$ above $6.5 \mathrm{l} / \mathrm{s}$ and $\mathrm{FEF}_{75-85}$ above $4 \mathrm{l} / \mathrm{s}$ were omitted, leaving data for 908 boys and 771 girls for $\mathrm{FEF}_{25-75}$ and 888 boys and 767 girls for $\mathrm{FEF}_{75-85}$. FVC and $\mathrm{FEF}_{75-85}$ for boys and girls had standard deviations proportional to mean value. For $\mathrm{FEF}_{25-75}$ the relation was linear but not proportional. Logarithmic (ln) transformation was therefore optimal for $\mathrm{FVC}$ and $\mathrm{FEF}_{75-85}$ and preferable to no transformation for $\mathrm{FEF}_{25-75}$. The regression equations to obtain predicted $\ln$ (value) and mean and standard deviation of antilogged residuals are shown in table 4 .

\section{Discussion}

The main aim of this paper was to demonstrate a method that can be used to analyse lung function data in children without violating the assumptions of regression analysis and analysis of variance, the main tools of practical data analysis. A secondary aim was to provide the means of calculating reference centiles and standard deviation scores for children aged 6.5 to 11.99 years.

We have reported results for children with at least two repeatable blows in this paper, in line with many published reports-that is, for $67.7 \%$ of the English white representative sample. However, the method, which was suggested by Bland et al, ${ }^{12}$ worked equally well on the data for the $90.0 \%$ with at least one valid blow. The method depends for its validity on a proportional relation between standard deviation and mean value as well as a normal distribution of lung function for fixed height

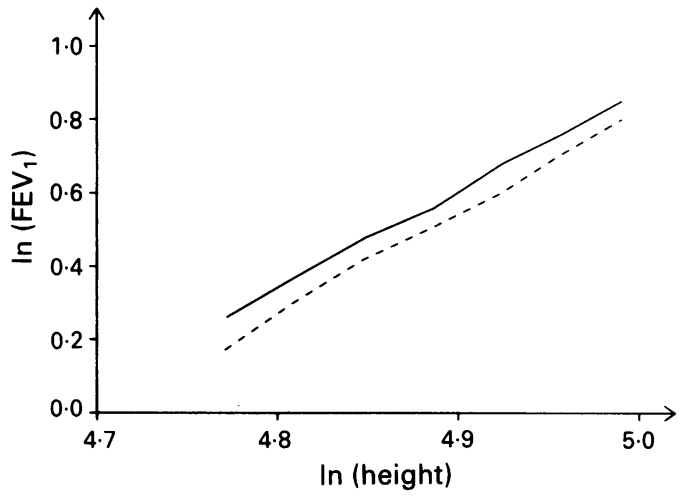

Figure 3 Mean $\ln \left(F E V_{1}\right)$ (boys

girls $\left.--_{-}\right)$plotted against mean $\ln ($ height $)$, for white children in English representative sample, in $5 \mathrm{~cm}$ height groups.

and age. These two properties are not unique to our data: Strang showed a regression line of $\mathrm{FEV}_{1}$ on height with symmetric $95 \%$ range at each height but increasing variance ${ }^{18}$ and Lunn commented that centiles bore a constant relation to the median, a consequence of the two properties. ${ }^{19}$ Others have used the natural logarithmic transformation to stabilise variance, ${ }^{8}$ but no other authors have combined this with the normal distribution. The need for a recommendation for the analysis of lung function in children is clearly shown in a recent paper in which, despite figures showing increasing variance of FVC and $F E V_{1}$ and a curvilinear relation with height, the author gave multiple regression equations for untransformed lung function on height and age. ${ }^{20}$ When data have the two properties of normal distribution and standard deviation proportional to the mean then the method described here should be used, or a statistically more sophisticated equivalent.

Comparison of response rates with those of other authors is difficult, as many report only the percentage of acceptable spirometric results among those tested, rather than the response rate in those eligible to take part, which is the relevant figure in epidemiological studies. However Kauffman et al reported that $70 \%$ of children provided acceptable forced time-volume curves. ${ }^{21}$

Although the standard deviation of $\mathrm{FEF}_{25-75}$ increased with mean value, the relation was not proportional, the transformation $\ln \left(\mathrm{FEF}_{25-75}+\right.$ $0.3)$ being preferable ${ }^{22}$ to $\ln \left(\mathrm{FEF}_{25-75}\right)$. However, use of natural logarithmic transformation is preferable to no transformation.

Table 3 Multiple regression of $\ln \left(F E V_{1}\right)$ on $\ln$ (height) and $\ln ($ age $)$ in white children in the English representative sample

\begin{tabular}{|c|c|c|c|c|c|c|}
\hline & \multicolumn{3}{|c|}{ Regression coefficients } & \multirow{2}{*}{$\begin{array}{l}\text { Multiple } \\
\text { correlation } \\
\text { coefficient }\left(R^{2}\right)\end{array}$} & \multicolumn{2}{|c|}{ Distribution of $\exp (\text { residual })^{\star}$} \\
\hline & Intercept & $\ln ($ height $)(S E)$ & $\ln ($ age $)(S E)$ & & Mean & $S D$ \\
\hline $\ln \left(\mathrm{FEV}_{1}\right)$ & $-11 \cdot 137$ & $2 \cdot 365(0.089)$ & $\begin{array}{c}\text { Boys }(n=909) \\
0.071(0 \cdot 089)\end{array}$ & $0 \cdot 65$ & $1 \cdot 0078$ & $0 \cdot 1129$ \\
\hline $\ln \left(\mathrm{FEV}_{1}\right)$ & $-10 \cdot 755$ & $2 \cdot 212(0 \cdot 104)$ & $\begin{array}{c}\text { Girls }(n=772) \\
0 \cdot 209(0.054)\end{array}$ & $0 \cdot 64$ & $1 \cdot 0107$ & $0 \cdot 1243$ \\
\hline
\end{tabular}

${ }^{\star}$ Lung function $\div$ predicted lung function. 
Figure 4 Distribution of residuals of $\ln \left(F E V_{1}\right)$ for white boys in English representative sample, with fitted normal curve of same mean and standard deviation.

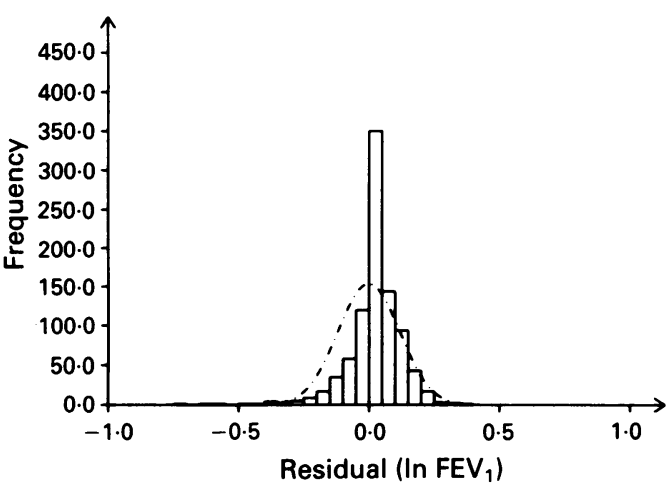

The important features of the analysis are, firstly, the logarithmic transformation before multiple regression analysis and, secondly, the antilogging of the residuals, or equivalently taking the ratio of actual to predicted lung function; predicted lung function is found by antilogging the predicted value from the multiple regression. We have used logarithms to base e, partly because they are natural in this context $\mathrm{t}^{22}$ and partly because of their use by most of the authors cited. However, base 10 can equally be used as results differ by only a multiplicative constant factor. Which terms are included in the prediction equation in addition to $\ln$ (height) are less important. We included $\ln$ (age), because although it explained a small proportion of the variation in lung function unaccounted for by height in our data, its importance increases with a wider age range. Quadratic and cubic terms in age were significant $(p<0.05)$ for some of the lung function measurements, but the extra variation explained was less than $1 \%$. There is slightly greater justification for inclusion of $\ln$ (weight) and $\ln$ (triceps skinfold thickness), which showed positive and negative relations respectively with both FVC and $\mathrm{FEV}_{1}$, in line with the finding of Cotes $e t$ al $^{23}$ of a positive relation of lung function with fat free mass/stature ${ }^{2}$. However, these two variables explained only $1 \%$ of the additional variation, and data on these two variables are unlikely to be available for routine use.

It is not surprising that various equations for height and age adjustment are found in published work, 5689 even when $\ln$ (lung function) has been used. Firstly, the terms will vary with the age range of the children in the study, as will the total variation explained by the multiple regression. Secondly, with large data sets,

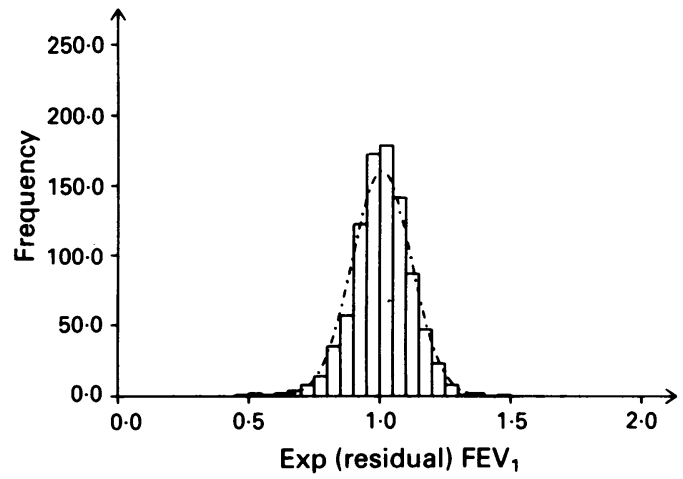

Figure 5 Distribution of antilogged residuals of ln $\left(F E V_{1}\right)$ for white boys in English representative sample, with fitted normal curve.

as required for centile estimation, very small departures from linearity can be significant but have negligible effect on predicted values.

We have not followed the recommendations of the American Thoracic Society ${ }^{14}$ completely, in that all measurements were taken from the blow with maximum FVC $+\mathrm{FEV}_{1}$. The recommendation to use maximum FVC and maximum $\mathrm{FEV}_{1}$ means that for the majority of children the values are taken from the same blow, ${ }^{14}$ but for a minority they are from different blows, so that the measurements have a different correlation in the two groups. However, the method of analysis in our study is appropriate to lung function data whichever criterion of selection is used.

Predicted $\ln$ (lung function) was calculated for children in the inner city groups and Scottish sample using the equations for the English representative sample. The means and standard deviations of the ratio of actual to predicted values are shown in table 5 . The four Indian subcontinent groups (Urdu, Gujarati, and Punjabi speaking and others) did not have significantly different mean values except for $\mathrm{FEF}_{25-75}$ in boys $(\mathrm{p}<0.05)$ and were combined, but the groups as shown together with the English represenative sample (table 3) had highly significantly different mean values $(p<0.001)$, except for $\mathrm{FEF}_{25-75}(\mathrm{p}>0.1)$ in boys. All the English inner city groups had lower lung function than the representative sample. The Afro-Caribbean children had the lowest mean values among the boys and the Indian subcontinent group among the girls. Scottish children had greater lung function by all parameters.

Table 4 Regression equations used to adjust $\ln (F V C), \ln \left(F E F_{25-75}\right)$, and $\ln \left(F E F_{75-85}\right)$ in white children in the English representative sample

\begin{tabular}{|c|c|c|c|c|c|c|}
\hline \multirow{2}{*}{$\begin{array}{l}\text { Dependent } \\
\text { variable }\end{array}$} & \multicolumn{3}{|c|}{ Regression coefficients } & \multirow{2}{*}{$\begin{array}{l}\text { Multiple } \\
\text { correlation } \\
\text { coefficient }\left(R^{2}\right)\end{array}$} & \multicolumn{2}{|c|}{ Distribution of $\exp (\text { residual })^{\star}$} \\
\hline & Intercept & $\ln ($ height $)(S E)$ & $\ln ($ age $)(S E)$ & & Mean & $S D$ \\
\hline $\begin{array}{l}\ln (F V C) \\
\ln \left(F E F_{25-75}\right) \\
\ln \left(F F_{75-85}\right)\end{array}$ & $\begin{array}{r}-11 \cdot 574 \\
-8 \cdot 717 \\
-10 \cdot 816\end{array}$ & $\begin{array}{l}2.508(0.083) \\
1.802(0.189) \\
2.050(0.329)\end{array}$ & $\begin{array}{c}\text { Boys } \\
0.016(0.042) \\
0.275(0.096) \\
0.214(0.166)\end{array}$ & $\begin{array}{l}0.69 \\
0.25 \\
0 \cdot 12\end{array}$ & $\begin{array}{l}1.0084 \\
1.0296 \\
1.0798\end{array}$ & $\begin{array}{l}0 \cdot 1087 \\
0 \cdot 2427 \\
0.3963\end{array}$ \\
\hline $\begin{array}{l}\ln (F V C) \\
\ln \left(F_{E F} F_{25-75}\right) \\
\ln \left(F^{\prime} F_{75-85}\right)\end{array}$ & $\begin{array}{r}-10 \cdot 808 \\
-9 \cdot 269 \\
-10 \cdot 705\end{array}$ & $\begin{array}{l}2.267(0.096) \\
1.853(0.212) \\
1.915(0.382)\end{array}$ & $\begin{array}{c}\text { Girls } \\
0.167(0.050) \\
0.413(0.109) \\
0.482(0.197)\end{array}$ & $\begin{array}{l}0.67 \\
0.30 \\
0.13\end{array}$ & $\begin{array}{l}1.0072 \\
1.0339 \\
1.0841\end{array}$ & $\begin{array}{l}0 \cdot 1162 \\
0 \cdot 2622 \\
0 \cdot 3882\end{array}$ \\
\hline
\end{tabular}

^Lung function $\div$ predicted lung function. 
Table 5 Distributions of exp(residual) in inner city and Scottish children, with residual taken from model for English representative sample. Values are means (SD)

\begin{tabular}{|c|c|c|c|c|}
\hline Ethnic group/sample & $F V C$ & $F E V_{l}$ & $F E F_{25-75}$ & $F E F_{75-85}$ \\
\hline Inner city: & \multicolumn{4}{|c|}{ Boys } \\
\hline White $(n=184)$ & $0.9896(0 \cdot 1156)$ & $0.9937(0.1265)$ & $1.0172(0.2447)$ & $1.0419(0.3851)$ \\
\hline Afro-Caribbean $(n=67)$ & $0.8435(0 \cdot 1044)$ & $0.8654(0.1100)$ & $1.0062(0.2899)$ & $0.9580(0.3793)$ \\
\hline Indian subcontinent $(n=241)$ & $0.8963(0 \cdot 1146)$ & $0.9125(0.1148)$ & $1.0288(0.3007)$ & $0.9964(0.3786)$ \\
\hline Other $(n=67)$ & $0.8968(0 \cdot 1632)$ & $0.9017(0.1548)$ & $0.9846(0.3019)$ & $0.9325(0.3593)$ \\
\hline Scottish (representative sample) $(n=195)$ & $1.0369(0.1023)$ & $1.0383(0 \cdot 1060)$ & $1.0676(0.2526)$ & $1.1189(0.4122)$ \\
\hline Inner city: & \multicolumn{4}{|c|}{ Girls } \\
\hline White $(n=195)$ & $0.9771(0 \cdot 1217)$ & $0.9851(0 \cdot 1262)$ & $1.0303(0.2639)$ & $1.0534(0.4212)$ \\
\hline Afro-Caribbean $(n=71)$ & $0.8937(0 \cdot 1058)$ & $0.8994(0 \cdot 1121)$ & $0.9751(0.2824)$ & $0.9307(0.3471)$ \\
\hline Indian subcontinent $(n=179)$ & $0 \cdot 8824(0 \cdot 1107)$ & $0.8958(0 \cdot 1187)$ & $1.0129(0.2936)$ & $1.0161(0.3984)$ \\
\hline Other $(n=46)$ & $0.9372(0 \cdot 1685)$ & $0.9459(0.1728)$ & $1.0012(0.2515)$ & $0.9974(0.3726)$ \\
\hline Scottish (representative sample) $(n=173)$ & $1 \cdot 0507(0 \cdot 1093)$ & $1 \cdot 0679(0 \cdot 1125)$ & $1 \cdot 1423(0 \cdot 2424)$ & $1 \cdot 2160(0.4719)$ \\
\hline
\end{tabular}

Standard deviation scores for the inner city and Scottish groups can be calculated using the prediction equations in tables 3 and 4 with the means and standard deviations in table 5 , as described in the appendix. This assumes that it is appropriate to compare children in these groups with their group mean, rather than assess children relative to a representative sample of the white majority. There is no agreement as yet over whether separate standards should be used for individual assessment of these children, ${ }^{24}$ but for analysis of lung function in relation to passive smoking or other environmental influences it is necessary to remove ethnic group differences.

Comparison of mean lung function with other authors is difficult, as existing standards for lung function were published ${ }^{1825-27}$ before the need to take age into account as well as height was recognised, and the studies generally include a greater age range than in the national study of health and growth. One exception is the paper by Dockery et al, which reports results for children aged 6 to 11 years in the United States six cities study. ${ }^{8}$ We calculated the differences between $\ln (\mathrm{FVC})$ and $\ln \left(F E V_{1}\right)$ and their published predictions as functions of height, age, weight, sex, and ethnic group for white children in the English representative sample and antilogged the result to give a ratio for children in the national study of health and growth to lung function of those in the six cities study. The mean ratio was 1.052 (SE 0.004) for FVC and 1.060 (SE 0.004) for $\mathrm{FEV}_{1}$ in boys and 0.969 (SE 0.004 ) and 1.000 (SE 0.004) respectively in girls. Our values for white boys in the English representative sample are therefore slightly greater when adjusted for height, age, and weight, but FVC slightly less in girls. Corresponding values for the white inner city sample were 1.030 (SE 0.013 ) for FVC and 1.044 (SE 0.010) for FEV in boys and 0.938 (SE 0.008) and 0.951 (SE 0.009 ) in girls respectively - that is, slightly greater for national study of health and growth boys and less for girls than the six cities children. If all children with at least one valid blow were included the white representative sample girls had greater FVC and $F_{1} V_{1}$ than the six cities girls.

Published centiles differ in their relation to mean or median because they have been calculated entirely on the untransformed scale or entirely on the log scale. Centiles constructed using Bland's method, ${ }^{12}$ although representing variation dependent on height, are symmetric about the median for a given height, unlike those calculated on the log scale. Formulations such as that of Cotes, who quoted a predicted value of the form a(height) ${ }^{b}$ with a standard deviation per cent, ${ }^{27}$ are equivalent to calculations on the log scale.

We confirm the findings of others that black children have lower lung function for height and age than their white counterparts in inner city areas. ${ }^{58}$ Our differences were $17 \%$ for FVC and $15 \%$ for $\mathrm{FEV}_{1}$ in boys, and $9 \%$ for each in girls. Patrick and Patel found differences of $13 \%$ and $12 \%$ for FVC and $F_{1}$ for children of Indian or Afro-Caribbean origin, but their data for the Afro-Carribbeans were on 82 children only, mainly aged over 12 years. Schwartz et al gave differences in $\ln$ (FVC) and $\ln \left(\mathrm{FEV}_{1}\right)$ of -0.114 and -0.0985 for black American children compared with white children-that is, $11 \%$ and $9 \%$ less respectively. ${ }^{6}$ This was after adjustment for $\ln$ (sitting height), which they reported as explaining $16 \%$ of the differences, so before the adjustment the differences were of the order of $13 \%$ and $11 \%$. Dockery et al gave differences of $12 \%$ for FVC and $13 \%$ for $\mathrm{FEV}_{1}{ }^{12}$ They also found greater variation in lung function in black children than in white children. The fact that sitting height explains part of the difference between black and white children ${ }^{68}$ seems to necessitate the use of separate stature and age adjusted standards for black children.

Schoenberg et al derived separate, and in our view unnecessarily complex, equations for black and white subjects aged 7 to 17 years, ${ }^{9}$ so comparison is difficult. They stated that differences were greater for FVC than for $\mathrm{FEV}_{1}$. We support their conclusion that a single "scaling factor", as proposed by Rossiter and Weill, ${ }^{28}$ in inappropriate, but mainly on the grounds that it may obscure increased variation.

Data on children of Indian subcontinent origin living in Western society are more scarce. Patrick and Patel studied 166 Indian boys and 108 Indian girls aged from 5 to 16 and found lower FVC and $F E V_{1}$ as reported above. ${ }^{5}$ Johnston et al found greater lung function in Indian children than in those of African origin, but differences were not significant. ${ }^{29}$ However, data on lung function were obtained in only 47 children of African origin and 40 of Indian 
origin. Our data on 241 boys and 179 girls are therefore a substantial additon to information. We confirm Johnston et al's suggestion of lung function intermediate between that of white inner city children and that of Afro-Caribbean origin for boys, but not for girls.

Our finding of greater lung function in Scottish children than in the English white representative sample, after height and age adjustment, is so far unexplained, although it may in some way be related to the lower response. The finding was not explained by differences in birth weight because, although we found lung function to increase with birth weight, as reported for adults by Barker et al,,$^{30}$ the relation was weak, and in our sample Scottish boys had lower mean birthweight than English boys in the representative sample.

For centile estimation correct description of residual variation is more important than inclusion of all significant terms in height and age in the prediction equation, but for the purposes of analysis in relation to other factors it is important also to incorporate all potentially confounding variables, including non-linear terms in height and age, and weight and triceps skinfold thickness or other measures of fatness. Effects such as passive smoking are likely to be small, and the potential for bias great.

Two approaches are possible-either to include all terms of interest and confounding variables in the age and height multiple regression equation or to calculate height and age adjusted standard deviation scores as described in the appendix and then carry out multiple regressions of these on the other independent variables. The latter is preferable because significance tests are then performed on a scale on which the residuals can be expected to be normally distributed with equal variance, and it allows the inclusion of groups with differing residual standard deviations, such as ethnic minority groups.

At least for FVC, $\mathrm{FEV}_{1}$ and $\mathrm{FEF}_{75-85}$, the properties of the data lead to the conclusion that the method of Bland et al should be adopted, ${ }^{12}$ and it may have application to many measurements in medicine. The method maximises use of the data, as children do not have to be divided into age or height subgroups, and requires estimation of only a small number of parameters. Its adoption for lung function should lead to more uniformity in presentation of results, so enabling authors to compare their results more easily than hitherto.

We thank all children, parents, teachers, doctors, administrators, nurses, and clerks in the areas and schools for their participation in the study; Professor WW Holland and the fieldworkers and administrators in our department for their work on the study; and Mrs A Childs for help with the manuscript The study is supported by the Department of Health and Scottish Home and Health Department.

\section{Appendix}

The results showed that $\mathrm{FEV}_{1} /$ predicted $\mathrm{FEV}_{1}$ is approximately normally distributed, mean 1.0078 for boys, 1.0107 for girls, and standard deviation 0.1129 and 0.1243 respectively (table 3 ). This can be used to calculate centiles of $F E V_{1}$ and standard deviation scores.
For example a boy of height $130 \mathrm{~cm}$, age 9.00 years has predicted $\ln \left(\mathrm{FEV}_{1}\right)=$

$$
-11 \cdot 137+2.365 \ln (130)+0.071 \ln (9)
$$

$=-11 \cdot 137+2.365 \times 4.868+0.071 \times 2 \cdot 197$

$=0.531$

So predicted $\mathrm{FEV}_{1}=\exp (0.531)=1.701$.

Therefore for centiles of $\mathrm{FEV}_{1}$ for boys height $130 \mathrm{~cm}$, age 9.00 years

$$
\frac{\mathrm{FEV}_{1}}{1.70} \text { is normally distributed, }
$$

mean 1.0078, standard deviation $0 \cdot 1129$.

So pth centile for boy height $130 \mathrm{~cm}$, age 9 years, is given by

$$
1 \cdot 70\left(1 \cdot 0078+0 \cdot 1129 \mathrm{z}_{\mathrm{p}}\right),
$$

where $z_{p}$ is the pth centile of the standard normal distribution.

Thus the 3rd centile is $1.70(1.0078-$ $0.1129 \times 1.8808$ ), which is 1.301 .

To obtain a standard deviation score for an individual child the predicted $\ln \left(\mathrm{FEV}_{1}\right)$ is found and antilogged as above. If a boy height $130 \mathrm{~cm}$, age 9, has an $\mathrm{FEV}_{1}$ of 1.5 then the ratio of $\mathrm{FEV}_{1}$ to its predicted value of 1.70 is 0.88 and his standard deviation score $=(0.88-1.0078) /$ $0 \cdot 1129=-1 \cdot 11$.

1 Hasselblad V, Humble CG, Graham MG, Anderson HS. Indoor environmental determinants of lung function in children. Am Rev Respir Dis 1981;123:479-85.

2 Tashkin DP, Clark VA, Simmons M, Reems C, Coulson AH, Bourque LB et al. The UCLA population studies of chronic obstructive respiratory disease. Am Rev Respir Dis 1984;129:891-7.

3 Lebowitz MD, Holberg CJ, Knudson RJ, Burrows B. Longitudinal study of pulmonary function development in childhood, adolescence and early adulthood. Am Rev Respir Dis 1987;136:69-75.

4 Primhak RA, Biggins JD, Tsanakas JN, Hatzimichael A, Milner RDG, Karpouzas JG. Factors affecting the peak expiratory flow rate in children. $\mathrm{Br} J$ Dis Chest 1984;78: 26-35.

5 Patrick JM, Patel A. Ethnic differences in the growth of lung function in children: a cross-sectional study in inner-city Nottingham. Ann Hum Biol 1986;13:307-15.

6 Schwartz J, Katz SA, Fegley RW, Tockman MS. Sex and race differences in the development of lung function. $\mathrm{Am}$ Rev Respir Dis 1988;138:1415-21.

7 Ware JH, Dockery DW, Spiro A, Speizer FE, Ferris BG Passive smoking, gas cooking, and respiratory health of children living in six cities. Am Rev Respir Dis 1984; 129:366-74.

8 Dockery DW, Berkey CS, Ware JH, Speizer FE, Ferris BG. Distribution of forced vital capacity and forced expiratory volume in one second in children 6 to 11 years of age. $\mathrm{Am}$ Rev Respir Dis 1983;128:405-12.

9 Schoenberg JB, Berk GJ, Bouhuys A. Growth and decay of pulmonary function in healthy blacks and whites. Respir Physiol 1978;33:367-93.

10 Yarnell JWG, St Leger AS. Respiratory morbidity and lung function in school children aged 7 to 11 years in South Wales and the West of England. Thorax 1981;36:842-6.

11 Cole TJ. Fitting smoothed centile curves to reference data (with discussion). Journal of the Royal Statistical Society (Series A) 1988;151:385-418.

12 Bland JM, Peacock JL, Anderson HR, Brook OG, de Curtis $M$. The adjustment of birthweight for very early gestational ages: two related problems in statistical analysis. Applied Statistics 1990;39:229-39.

13 Chinn S, Rona RJ. Quantifying the health effects of passive smoking on British children aged 5 to 11 years. J Epidemiol Community Health 1991;45:188-94.

14 American Thoracic Society. Standardisation of spirometry-1987 update. Am Rev Respir Dis 1987;136: 1285-98.

15 Tanner JM, Whitehouse RH, Takaishi M. Standards from birth to maturity for height, weight, height velocity and weight velocity. British children, 1965. Arch Dis Child 1966;41:454-71.

16 Payne $\mathrm{CD}$, ed. The GLIM system release 3.77. Oxford Numerical Algorithms Group, 1985.

17 Chinn S. The assessment of methods of measurement. Stat 
Med 1990;9:351-62.

18 Strang LB. The ventilatory capacity of normal children. Thorax 1959;14:305-10.

19 Lunn JE. Respiratory measurements of 3556 Sheffield schoolchildren. British Journal of Preventive and Social Medicine 1965;19:115-22.

20 Shamssain MH. Forced expiratory indices in normal black Southern African children aged 6-19 years. Thorax 1991;46:175-9.

21 Kauffmann F, Tager IB, Munoz A, Speizer FE. Familial factors related to lung function in children aged 6-10 years. Am J Epidemiol 1989;129:1289-99.

22 Chinn S. Statistics in respiratory medicine. III Scale, parametric methods, and transformations. Thorax 1991; 46:536-8.

23 Cotes JE, Dabbs JM, Hall AH, Heywood C. Sitting height, fat-free mass and body fat as reference values for lung function in healthy British children: comparison with stature. Ann Hum Biol 1979;6:307-14.

24 Chinn S, Price CE, Rona RJ. Need for new reference curves for height. Arch Dis Child 1989;64:1545-53.
25 Godfrey S, Kamburoff PL, Nairn JR. Spirometry, lung volumes and airway resistance in normal children aged 5 to 18 years. Br J Dis Chest 1970;64:15-23.

26 Dickman ML, Schmidt CD, Gardner RM. Spirometric standards for normal children and adolescents (ages years through 18 years). Am Rev Respir Dis 1971;104: 680-7.

27 Cotes JE. Lung function: assessment and application in medicine. 4th ed. Oxford: Blackwell Scientific Publications 1979:340.

28 Rossiter CE, Weill $\mathrm{H}$. Ethnic differences in lung function: evidence for proportional differences. Int $J$ Epidemio 1974;3:55-61.

29 Johnston IDA, Bland JM, Anderson HR. Ethnic variation in respiratory morbidity and lung function variation in childhood. Thorax 1987;42:542-8.

30 Barker DJP, Godfrey KM, Fall C, Osmond C, Winteer PD Shaheen SO. Relation of birth weight and childhood respiratory infection to adult lung function and death from chronic obstructive airways disease. BMJ 1991;303: 671-5. 